\title{
Uso da restrição hídrica na detecção de Alternaria dauci e Alternaria radicina em sementes de cenoura (Daucus carota)
}

\author{
Enia M. de Carvalho ${ }^{1}$, Ursula A. da Silva ${ }^{1}$ \& Denise C.G.A. Rodrigues ${ }^{2}$ \\ ${ }^{1}$ Departamento de Entomologia e Fitopatologia, Universidade Federal Rural do Rio de Janeiro, 23851-970, Seropédica, RJ, \\ Brasil; ${ }^{2}$ Universidade do Estado do Rio de Janeiro, Faculdade de Tecnologia, 27537-000, Resende, RJ, Brasil
}

Autor para correspondência: Enia M. de Carvalho, e-mail: eniacarvalho@yahoo.com.br

\begin{abstract}
RESUMO
Para avaliar a viabilidade do uso da técnica de restrição hídrica na detecção dos fungos Alternaria dauci e $A$. radicina em sementes de cenoura pelo método de incubação em substrato de papel de filtro, foram utilizados os solutos manitol, $\mathrm{NaCl}$ e manitol $+\mathrm{NaCl}$ para ajuste do potencial osmótico a - 0,$4 ;-0,6 ;-0,8 ;-1,0$ e 1,2 MPa. Inicialmente, o índice de crescimento micelial (ICM) dos fungos foi avaliado em meio de cultura BDA ajustado a diferentes potenciais osmóticos. A seguir, as sementes foram incubadas nas mesmas condições, avaliando-se o índice de velocidade de germinação (IVG) e o comprimento de raiz. Foram avaliadas também a incidência e a porcentagem das sementes cobertas por propágulos dos patógenos (PSCPP) em sementes inoculadas e submetidas ao teste de sanidade em substrato de papel umedecido com soluções osmóticas. Observou-se que a restrição hídrica favoreceu o ICM de $A$. dauci. A germinação das sementes em substrato osmoticamente modificado foi reduzida a 100\%. Pela incidência e PSCPP, verificou-se que a restrição hídrica induzida por $\mathrm{NaCl}$ e/ou pela mistura manitol $+\mathrm{NaCl}$ proporcionou índices maiores ou próximos ao teste padrão, demonstrando a viabilidade do uso da técnica de restrição hídrica na detecção de $A$. dauci e $A$. radicina.
\end{abstract}

Palavras-chave: Blotter test, patologia de sementes, germinação, potencial osmótico.

\begin{abstract}
Use of water restriction for the detection of Alternaria dauci and Alternaria radicina in carrot seeds (Daucus carota)

To evaluate the viability of water restriction technique in the detection of the fungi Alternaria dauci and $A$. radicina in carrot seeds by blotter test, the solutes mannitol, $\mathrm{NaCl}$ and mannitol $+\mathrm{NaCl}$ were used to adjust water potentials of $-0.4 ;-0.6 ;-0.8 ;-1.0$ and $1.2 \mathrm{MPa}$. Initially, mycelial growth index (MGI) of the two fungi was evaluated on PDA medium at modified water potential. Seeds were incubated on culture medium under modified water potential, in order to evaluate the germination speed index (GSI) and root length. In the last step, incidence and inoculum intensities of the pathogens (PSCP) on the seeds were evaluated by the blotter test with osmotic compounds. Water restriction technique showed to be beneficial to $A$. dauci MGI. Seed germination in osmotic modified substrate was reduced up to $100 \%$. On the basis of incidence and PSCP, it was verified that water restriction induced by $\mathrm{NaCl}$ and/or by the mixture mannitol $+\mathrm{NaCl}$ provided indexes that were higher or close to those obtained in the standard blotter test, demonstrating the viability of the water restriction technique for the detection of $A$. dauci and A. radicina.
\end{abstract}

Keywords: Blotter test, seed pathology, germination, water potential.

\section{INTRODUÇÃO}

Entre as espécies patogênicas à cenoura, Alternaria dauci (J.G. Kühn) J.W. Groves \& Skolko e Alternaria radicina Meier, Drechsler \& E.D. Eddy, são os mais importantes e encontram-se associadas a sementes (Soteros, 1979; Tylkowska, 1992), podendo causar queima das folhas e podridão das raízes, respectivamente. Ambos os patógenos podem causar também o tombamento de plântulas (Fancelli, 1997). A semente é considerada a principal via de disseminação (Pryor et al., 1997; Halfed-Vieira et al., 2000; Souza et al., 2001). Entre os métodos de detecção de Alternaria spp. em sementes de cenoura, o 'blotter test' é a técnica comumente utilizada (Neergaard, 1979). Entretanto, neste teste, a rápida germinação das sementes durante o período de incubação prejudica a avaliação dos fungos presentes e pode comprometer a validade dos resultados devido a possíveis contaminações secundárias entre as sementes e o exterior do recipiente (Machado, 1988).

Para controlar a germinação das sementes de cenoura no teste de sanidade, recomenda-se a técnica do congelamento durante 24 horas após um período de embebição das sementes por 24 horas (ISTA, 2003). No entanto, o congelamento pode criar condições favoráveis para o desenvolvimento de bactérias e fungos saprofíticos (Limonard, 1968), além dos custos envolvidos na aquisição de equipamentos de congelamento e a limitação do fluxo de análise de um maior número de amostras que devem 
ser submetidas a esse processo em curto período de tempo (Machado et al., 2003).

A restrição hídrica em substratos utilizados para inocular fungos em sementes mostrou-se procedimento eficaz no controle da germinação das sementes, sem afetar o desenvolvimento da maioria dos fungos já testados (Carvalho, 1999; Costa etal., 2003; Carvalho et al., 2004). Em teste de sanidade de sementes, a técnica de restrição hídrica foi ajustada para culturas do arroz e feijão (Coutinho et al., 2001), algodoeiro (Machado et al., 2007), soja (Machado et al., 2003), trigo (Celano, 2003) e sorgo (Magalhães, 2005). Neste caso, o potencial osmótico não interfere de forma negativa na incidência e na área superficial da semente coberta por propágulos do patógeno. A incubação é suficiente para retardar a germinação das sementes por um período de tempo necessário para o desenvolvimento do patógeno, que é aproximadamente sete dias. O objetivo deste trabalho foi avaliar a viabilidade do uso da técnica de restrição hídrica na detecção de $A$. dauci e $A$. radicina em sementes de cenoura pelo método de incubação em substrato de papel, como alternativa ao congelamento.

\section{MATERIAL E MÉTODOS}

Os fungos $A$. dauci e $A$. radicina foram isolados de sementes de cenoura, identificados com base nas características morfológicas e submetidos ao teste de patogenicidade. Em todos os ensaios, foram utilizadas sementes da cultivar Brasília, proveniente do Centro Nacional de Pesquisa de Hortaliças da Embrapa. Para avaliar o efeito da restrição hídrica sobre o desenvolvimento de $A$. dauci e $A$. radicina, foi determinado o crescimento micelial de $A$. dauci e $A$. radicina em meio de cultura batata - dextrose - ágar (BDA) modificado com os solutos manitol, $\mathrm{NaCl}$ e a mistura de manitol (50\%) e $\mathrm{NaCl}(50 \%)$, com os potenciais osmóticos ajustados em - 0,$4 ;-0,6 ;-0,8$; $-1,0$ e -1,2 MPa (Mega Pascal). Em cada placa de Petri, foi adicionado, ao centro, um disco de $5 \mathrm{~mm}$ de diâmetro de meio de cultura contendo os fungos cultivados por sete dias. As placas foram acondicionadas em câmara de crescimento com temperatura regulada a $25^{\circ} \mathrm{C}$ e fotoperíodo de 12 horas. $\mathrm{O}$ diâmetro das colônias foi avaliado diariamente e o índice de crescimento micelial (ICM) determinado utilizando-se a fórmula descrita por Oliveira (1991).

A germinação das sementes em relação à restrição hídrica foi avaliada pela exposição das sementes ao meio de cultura BDA, modificado conforme descrito acima. As avaliações foram realizadas fazendo-se contagens diárias das sementes germinadas, calculando em seguida o Índice de Velocidade de Germinação (IVG) conforme a fórmula de Maguire (1962). Entre as sementes germinadas foi avaliado o comprimento da raiz principal.

O delineamento utilizado para avaliar o crescimento das colônias fúngicas e a germinação das sementes foi o inteiramente casualizado (DIC), em esquema fatorial $3 \times 5$ +1 , sendo as combinações entre solutos (manitol, $\mathrm{NaCl}$ e a mistura manitol e $\mathrm{NaCl})$ e potenciais osmóticos $(-0,4 \mathrm{MPa}$, $-0,6 \mathrm{MPa},-0,8 \mathrm{MPa},-1,0 \mathrm{MPa}$ e $-1,2 \mathrm{MPa})$. O tratamento testemunha (adicional) foi constituído por BDA sem adição de restritores. No teste para avaliar o crescimento micelial, a parcela experimental foi constituída por uma placa de Petri de $9 \mathrm{~cm}$ de diâmetro, perfazendo-se cinco repetições. No teste de germinação de sementes, a parcela foi constituída de uma placa de Petri de $15 \mathrm{~cm}$ de diâmetro com 50 sementes, totalizando-se quatro repetições.

Os testes de sanidade para avaliar o desenvolvimento de $A$. dauci e $A$. radicina sobre a semente foram realizados separadamente. Para cada patógeno, as sementes foram divididas em seis frações, sendo uma das frações sem inoculação e cinco frações inoculadas nos períodos de 24, 48, 72, 96 e 120 horas. Após a inoculação, as sementes foram misturadas e homogeneizadas, obtendo-se uma amostra composta, a qual foi submetida à assepsia com hipoclorito de sódio $1 \%$ durante 10 minutos.

Foram preparadas soluções osmóticas em água, com os mesmos solutos e potenciais osmóticos descritos anteriormente. Os tratamentos testemunhas foram constituídos por sementes incubadas em substrato de papel com congelamento e sem congelamento ("blotter test" padrão). Ao final do período de incubação (sétimo dia), foram avaliadas a incidência e a porcentagem das sementes cobertas pelo propágulo do patógeno (PSCPP) de A. dauci e $A$. radicina .

Para determinar a PSCPP, foram atribuídas notas variando de 0 a 3 ( 0 - semente sem propágulos do patógeno; 1 - sementes com $1 \%$ a $10 \%$ da área superficial recoberta por propágulos do patógeno; 2 - sementes com $11 \%$ a $50 \%$ da área superficial recoberta por propágulos do patógeno e; 3 - sementes com 51 a $100 \%$ da área superficial recoberta por propágulos do patógeno). As notas foram ponderadas em relação à média, adaptando-se o índice de Mckinney (1923).

O ensaio constou de 17 tratamentos em delineamento inteiramente casualizado, com 4 repetições de 50 sementes em esquema fatorial $3 \times 5+2$ (3 solutos, 5 potenciais osmóticos e dois tratamentos adicionais). A análise estatística foi realizada utilizando-se o programa SISVAR (Ferreira, 2000). Nas análises de variância, foram determinados os efeitos dos solutos, dos potenciais osmóticos e as interações entre soluto, potencial osmótico e tratamentos adicionais. Para o fator qualitativo (solutos), utilizou-se o teste de Tukey na comparação das médias. Equações de regressão foram ajustadas aos dados das variáveis analisadas quando verificado efeito significativo $(p \leq 0,05)$ do potencial osmótico.

\section{RESULTADOS E DISCUSSÃO}

\section{Índice de Crescimento Micelial (ICM)}

$\mathrm{Na}$ avaliação do ICM de $A$. dauci foi verificado efeito significativo na interação soluto e potencial $(\mathrm{p} \leq 1 \%)$. Entre os solutos testados, a adição de manitol proporcionou ICM 
maior ou igual aos demais solutos utilizados (Tabela 1). A redução do potencial osmótico, induzida por manitol e pela mistura de manitol e $\mathrm{NaCl}$, nos potenciais $-1,0 \mathrm{e}-1,2$, resultou no aumento do ICM. Os solutos utilizados proporcionaram maior ICM em relação ao tratamento testemunha (BDA) em todos os potenciais osmóticos testados (Figura 1a). Da mesma forma foi observado que o crescimento das colônias de Colletotrichum lindemuthianum foi favorecido pela adição de manitol ao meio BDA (Carvalho et al., 2001). Coutinho et al. (2001) observaram que a restrição hídrica do meio BDA, nos potencias - $-0,6$ e $-0,7 \mathrm{MPa}$, induzida por manitol, $\mathrm{KCl}$ e $\mathrm{NaCl}$ não afetou ou favoreceu o crescimento micelial dos Colletotrichum lindemuthianum, Fusarium oxysporum f. sp. phaseoli e Rhizoctonia solani.

$\mathrm{Na}$ avaliação do ICM de Alternaria radicina, foram observadas diferenças entre os potenciais osmóticos ( $p$ $\leq 1 \%$ ), reduzindo-se o ICM, com a redução do potencial osmótico (Figura 1b). Entretanto, no potencial $-0,6$ e $0,8 \mathrm{MPa}$, a redução no ICM foi de apenas $0,17 \%$ e $13 \%$ respectivamente, enquanto no potencial $-1,0 \mathrm{MPa}$, observou-se uma redução de $24 \%$ comparada ao tratamento testemunha.

\section{Germinação das sementes}

$\mathrm{Na}$ avaliação do índice de velocidade de germinação das sementes e comprimento de raízes, pelo método de incubação em substrato agarizado, foi observado efeito significativo $(\mathrm{p} \leq 0,01)$ para o fator potencial osmótico. Nos potenciais osmóticos mais negativos, o índice de velocidade de germinação das sementes decresceu, em todos os solutos utilizados (Figura 2a). As maiores reduções na velocidade de germinação foram observadas a partir do potencial $-0,8 \mathrm{MPa}$, proporcionando um decréscimo de $93 \%$ na velocidade de germinação das sementes de cenoura em relação à testemunha. $\mathrm{O}$ mesmo foi observado para o fator comprimento de raiz (Figura $2 b$ ).

No tratamento sem adição de soluto ao meio, o comprimento médio de raiz foi $3,03 \mathrm{~cm}$ enquanto nos potencias $-0,8 \mathrm{MPa}$ e $-1,0 \mathrm{MPa}$, esse valor decresceu para $0,20 \mathrm{~cm}$ e $0,02 \mathrm{~cm}$ respectivamente. No potencial $1,2 \mathrm{MPa}$, a germinação da semente foi inibida durante o período estudado. A alta eficácia da técnica de restrição hídrica no controle da germinação das sementes já havia sido demonstrada para as sementes de arroz e feijão (Carvalho, 1999; Coutinho et al., 2001; Costa et al. 2003),

TABELA 1 - Dados referentes ao Índice de Crescimento Micelial de A. dauci, em meio de cultura BDA osmoticamente modificado

\begin{tabular}{lccccc}
\hline \hline \multirow{2}{*}{ Soluto } & \multicolumn{5}{c}{ Potenciais 0 osmóticos (MPa) } \\
\cline { 2 - 6 } & $\mathbf{- 0 , 4}$ & $\mathbf{- 0 , 6}$ & $\mathbf{- 0 , 8}$ & $\mathbf{- 1 , 0}$ & $\mathbf{- 1 , 2}$ \\
\hline Manitol & $5,14 \mathrm{a}$ & $5,75 \mathrm{a}$ & $5,74 \mathrm{a}$ & $6,08 \mathrm{a}$ & $5,76 \mathrm{a}$ \\
$\mathrm{NaCl}$ & $5,17 \mathrm{a}$ & $5,19 \mathrm{ab}$ & $5,18 \mathrm{a}$ & $4,81 \mathrm{~b}$ & $5,01 \mathrm{~b}$ \\
Manitol $+\mathrm{NaCl}$ & $4,48 \mathrm{~b}$ & $5,13 \mathrm{~b}$ & $5,26 \mathrm{a}$ & $5,66 \mathrm{a}$ & $5,79 \mathrm{a}$ \\
Média & & & & & 5,34 \\
BDA & & & & & 4,47 \\
CV (\%) & & & & 7,31 \\
\hline
\end{tabular}

${ }^{*}$ Médias com a mesma letra na coluna são estatisticamente iguais pelo teste $\mathrm{F}(\mathrm{p} \leq 5 \%)$.

${ }^{1} \mathrm{~A}$ testemunha BDA é inferior à média dos tratamentos com restrição hídrica pelo teste $\mathrm{F}$ ( $\mathrm{p}$ $\leq 5 \%)$
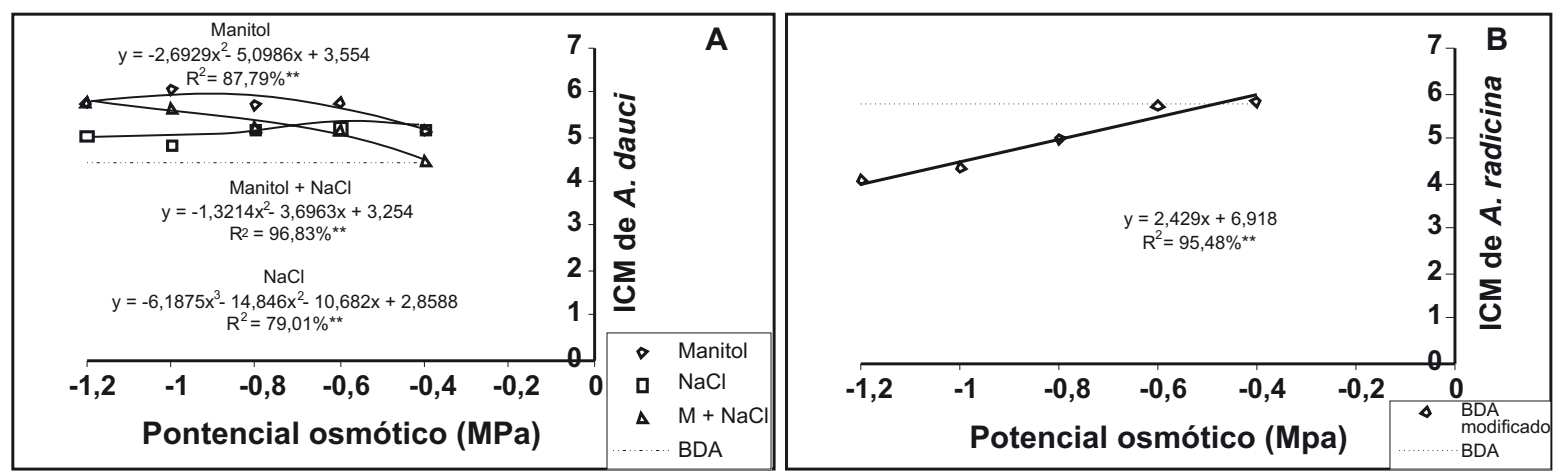

FIGURA 1 - A. Índice de crescimento micelial dos fungos A. dauci (a); e B. A. radicina em meio BDA osmoticamente modificado. 

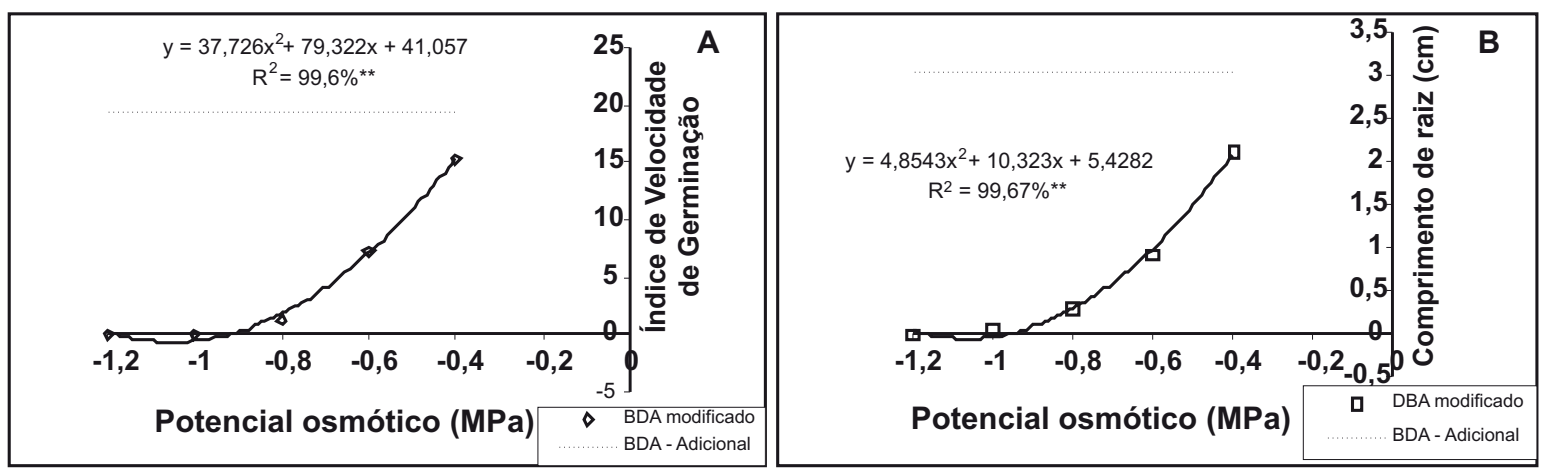

FIGURA 2 - A. Índice de velocidade de germinação; e B. e comprimento de raiz de sementes submetidas à incubação em meio BDA osmoticamente modificado.

trigo (Celano, 2003; Farias et al., 2003), soja (Machado et al., 2003) e algodão (Machado et al., 2007).

\section{Teste de sanidade}

Para A. dauci, os fatores soluto e potencial osmótico foram significativos pelo teste $\mathrm{F}$ para as variáveis incidência e PSCPP. Entre os solutos testados, o cloreto de sódio $(\mathrm{NaCl})$ proporcionou maior incidência e PSCPP, em relação à mistura manitol $+\mathrm{NaCl}$ (Tabela 2). Entre os potenciais testados, foi verificado que a redução do potencial osmótico estimulou o desenvolvimento do patógeno (Figura 3a). Para esse patógeno, não houve diferença significativa entre os tratamentos e as testemunhas. Farias et al. (2003), estudando a interferência da restrição hídrica no teste de sanidade de sementes de trigo, verificaram que a incidência de Alternaria sp. foi maior quando se utilizou o $\mathrm{NaCl}$, em detrimento aos demais solutos estudados e à testemunha sem congelamento ('blotter test' padrão).

Ao analisar a incidência de $A$. radicina verificouse que os fatores estudados não foram significativos pelo teste $\mathrm{F}$, sendo significativo, apenas as médias do fatorial vs. adicional, assim, os tratamentos com os solutos nos diversos potenciais proporcionaram maior incidência de $A$. radicina $(87,2 \%)$, em relação às testemunhas $(82 \%)$. A incidência de A. radicina nos potenciais osmóticos $-0,8 \mathrm{MPa}$ e $-1,0 \mathrm{MPa}$, induzidos por $\mathrm{NaCl}$, foi de $87 \%$ e de $86,5 \%$, respectivamente, enquanto que no 'blotter test' padrão, a incidência do mesmo fungo foi de $83,5 \%$ e no 'blotter test' com congelamento, a incidência apresentada foi de $80,5 \%$.

Ao analisar os valores de PSCPP para A. radicina, observou-se que a interação entre os solutos utilizados e os potenciais osmóticos, foi significativa pelo teste F. Entre os solutos utilizados, o $\mathrm{NaCl}$ e a mistura $\mathrm{NaCl}+$ manitol, favoreceram o desenvolvimento de $A$. radicina, para a maioria dos potenciais testados, com exceção apenas para o potencial $-0,4 \mathrm{MPa}$, onde o $\mathrm{NaCl}$ proporcionou menor valor de PSCPP (Tabela 3). Os potenciais osmóticos de -0,6, -0,8 e -1,0 MPa induzidos por $\mathrm{NaCl}$ estimularam a PSCPP em relação ao menor potencial estudado (Figura 3b).
Entre os tratamentos testemunha, foi observado que o congelamento favoreceu a PSCPP de A. radicina (Tabela 3 ). Entretanto, segundo Celano (2003), o crescimento fúngico pode ser favorecido pelo método de congelamento, uma vez que, por ocasião do congelamento, as células das sementes são rompidas, resultando na drenagem de exsudados no papel, propiciando assim o desenvolvimento de fungos, o que pode resultar na contaminação entre sementes durante o teste de sanidade.

O uso da técnica de restrição hídrica, induzida por $\mathrm{NaCl}, \mathrm{KCl}$ e manitol, em diferentes potenciais osmóticos, não interferiu na detecção dos fungos associados às sementes de arroz e feijão (Coutinho et al., 2001. Da mesma forma, Machado et al. (2007) constataram que a restrição hídrica produzida por manitol e $\mathrm{NaCl}$ no potencial osmótico -1,0 MPa não interferiu no desenvolvimento e detecção dos fungos F. oxysporum f.sp. vasinfectum, Botryodiplodia theobromae, Colletotrichum gossypii e C. gossypii var. cephalosporioides em sementes de algodoeiro submetidas ao teste de sanidade pelo método de incubação em substrato de papel. Farias et al. (2003), após o teste com vários solutos na análise sanitária de sementes de trigo e milho, indicaram o uso de $\mathrm{KCl}$ e $\mathrm{NaCl}$ para o controle da germinação das sementes.

Nopresente trabalho, o crescimento de $A$. radicina, em substrato osmoticamente modificado com $\mathrm{NaCl}$ restringiuse à superfície da semente, sem no entanto influenciar de forma negativa na incidência, ao contrário dos solutos, em que a colônia fúngica apresentou um diâmetro maior, desenvolvendo-se sobre o papel, como pode ser observado na Figura 4. O desenvolvimento da colônia fúngica sobre o papel pode levar a contaminações secundárias durante o teste de sanidade.

Além do aspecto de contaminação entre sementes durante a germinação destas em teste de incubação em substrato de papel, outro fator limitante tem sido a dificuldade de o técnico realizar leitura em sementes germinadas. Neste estudo, foi necessário, em média 16 minutos a mais para realizar leitura em uma amostra de sementes germinadas, quando comparado à mesma amostra 
TABELA 2 - Médias referentes à incidência e à porcentagem da semente de cenoura recoberta por propágulos de $A$. dauci (PSCPP), submetidas ao teste de sanidade de incubação em substrato de papel osmoticamente modificado com os solutos manitol, $\mathrm{NaCl}$ e manitol $+\mathrm{NaCl}$

\begin{tabular}{lll}
\hline \hline Soluto & Incidência $^{*}$ & PSCPP* $^{*}$ \\
\hline Manitol & $6,00 \mathrm{ab}$ & $3,76 \mathrm{ab}$ \\
$\mathrm{NaCl}$ & $6,56 \mathrm{a}$ & $4,58 \mathrm{a}$ \\
Manitol $+\mathrm{NaCl}$ & $4,92 \mathrm{~b}$ & $3,22 \mathrm{~b}$ \\
Média dos tratamentos $^{1}$ & 5,83 & 3,85 \\
Média das testemunhas $^{2}$ & 6,71 & 4,62 \\
$\mathrm{CV}(\%)$ & 35,30 & 30,19 \\
\hline
\end{tabular}

Os dados foram transformados em $\sqrt{x}$.

*Médias seguidas pela mesma letra na coluna não diferem entre si pelo teste de Tukey $(\mathrm{p} \leq 0,05)$.

1, ${ }^{2}$ Diferenças entre médias dos tratamentos e média das testemunhas não foram significativas pelo teste $\mathrm{F}(\mathrm{p} \leq 5 \%)$..

TABELA3 - Médias referentes à porcentagem da semente de cenoura recoberta por propágulos de $A$. radicina (PSCPP), submetidas ao teste de sanidade, incubação em substrato de papel osmoticamente modificado com os solutos manitol, $\mathrm{NaCl}$ e manitol $+\mathrm{NaCl}$, em diferentes potenciais osmóticos

\begin{tabular}{lccccc}
\hline \hline \multirow{2}{*}{ Soluto } & \multicolumn{5}{c}{ Potenciais osmóticos (MPa) } \\
\cline { 2 - 6 } & $\mathbf{- 0 , 4}$ & $\mathbf{- 0 , 6}$ & $\mathbf{- 0 , 8}$ & $\mathbf{- 1 , 0}$ & $\mathbf{- 1 , 2}$ \\
\hline Manitol & $64,83 \mathrm{a}^{1}$ & $49,50 \mathrm{~b}$ & $40,83 \mathrm{~b}$ & $41,84 \mathrm{~b}$ & $41,67 \mathrm{~b}$ \\
$\mathrm{NaCl}$ & $46,33 \mathrm{~b}$ & $59,50 \mathrm{a}$ & $56,00 \mathrm{a}$ & $56,00 \mathrm{a}$ & $49,50 \mathrm{ab}$ \\
Manitol + $\mathrm{NaCl}$ & $60,33 \mathrm{a}$ & $56,50 \mathrm{ab}$ & $52,00 \mathrm{a}$ & $54,17 \mathrm{a}$ & $58,50 \mathrm{a}$ \\
Média dos tratamentos ${ }^{1}$ & & & & 52,50 \\
'Blotter test' com congelamento & & & & $71,83 \mathrm{~A}$ \\
'Blotter test' padrão & & & & $60,33 \mathrm{~B}$ \\
Média das testemunhas ${ }^{2}$ & & & & 66,08 \\
CV (\%) & & & & 10,72 \\
\hline
\end{tabular}

${ }^{*}$ Médias seguidas pela mesma letra na coluna não diferem entre si pelo teste de Tukey $(\mathrm{p} \leq 0,05)$.

${ }^{1,2}$ Diferenças de densidade do inóculo entre médias dos tratamentos e média das testemunhas foram significativas pelo teste $\mathrm{F}(\mathrm{p} \leq 5 \%)$.

$\mathrm{A}, \mathrm{B}=$ Teste $\mathrm{F}$ significativo a $5 \%$ de probabilidade para tratamentos adicionais.
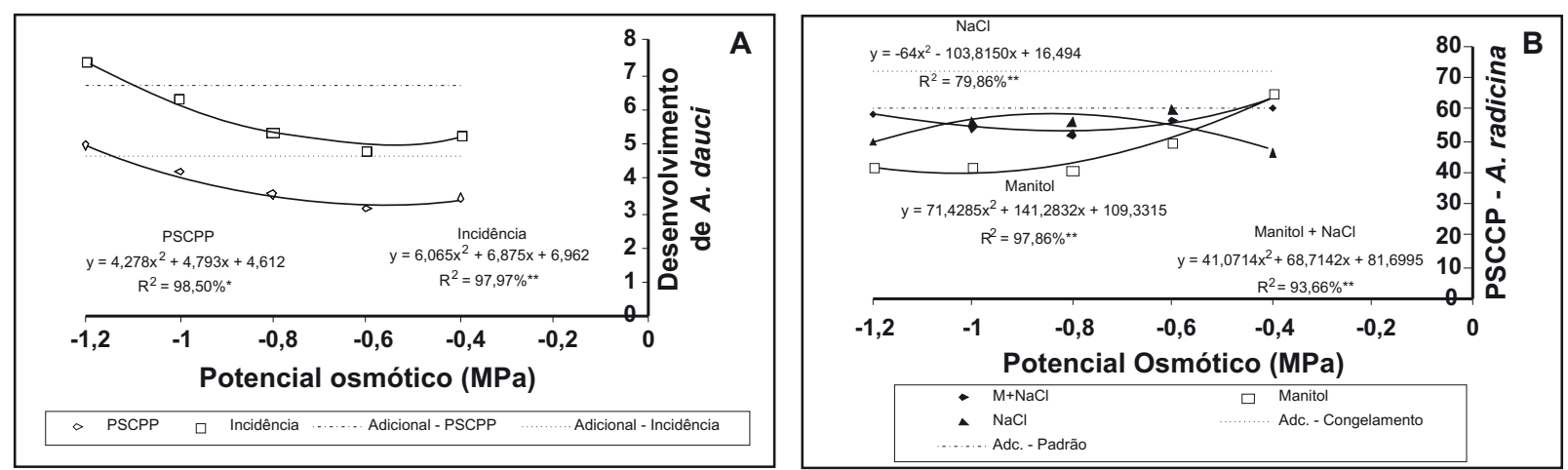

FIGURA 3 - Análise de regressão relacionando a incidência e PSCPP de $A$. dauci (a) e PSCPP de $A$. radicina (b) em diferentes potenciais osmóticos. 


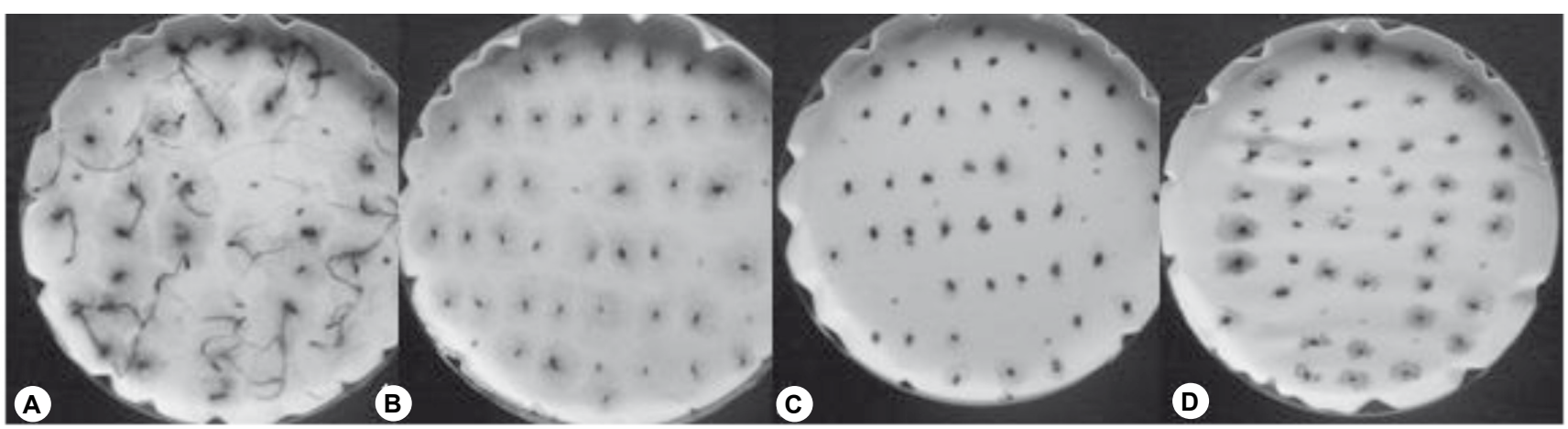

FIGURA 4 - A. Sementes de cenoura submetidas à análise sanitária pelos métodos de incubação em papel de filtro umedecido com água; B. água com manitol (-1,0MPa); C. água com $\mathrm{NaCl}$ (-1,0MPa); e D. água com manitol + $\mathrm{NaCl}(-1,0 \mathrm{MPa})$.

submetida ao condicionamento osmótico de $-1.0 \mathrm{MPa}$ (Figura 4). Os dados apresentados permitem concluir que o teste de sanidade com restrição hídrica, apresenta potencial para ser utilizado na detecção de $A$. dauci e $A$. radicina em sementes de cenoura. $\mathrm{O}$ condicionamento osmótico de -1.0 $\mathrm{MPa}$, induzido por $\mathrm{NaCl}$, pode ser uma alternativa ao uso do congelamento na detecção de $A$. dauci e $A$. radicina. Ressalta-se, no entanto, a necessidade de realizar testes confirmativos e o uso de maior número de lotes de sementes com ocorrência natural desses patógenos.

\section{AGRADECIMENTOS}

Os autores agradecem à Fundação de Amparo à Pesquisa do Estado do Rio de Janeiro - FAPERJ pelo auxílio financeiro ao primeiro autor, à Empresa de Pesquisa Agropecuária do Estado do Rio de Janeiro - PESAGRO pelo espaço físico cedido, à EMBRAPA Hortaliças pelo fornecimento de sementes e a Helena G. Montano por valiosas sugestões durante a condução do experimento.

\section{REFERÊNCIAS BIBLIOGRÁFICAS}

Carvalho JCB (1999) Uso da restrição hídrica na inoculação de Colletotrichum lindemuthianum em sementes de feijão (Phaseolus vulgaris L.). Dissertação de Mestrado. Universidade Federal de Lavras. Lavras MG.

Carvalho EM, Machado JC, von Pinho EVR, Pozza EA, Prado PER (2004) Relação do tamanho de sementes de milho e doses de fungicida no controle de Stenocarpella maydis. Fitopatologia Brasileira 29:389-393.

Carvalho JCB, Machado JC, Vieira MGGC (2001) Crescimento micelial de Colletotrichum lindemuthianum em relação à restrição hídrica do substrato agarizado. Ciência e Agrotecnologia 25:9991005.

Celano MM (2003) Uso da restrição hídrica em teste de sanidade e em estudos sobre a interação entre fungos e sementes de trigo. Dissertação de Mestrado. Universidade Federal de Lavras. Lavras MG.
Costa MLN, Machado JC, Guimarães RM, Guimarães RM, Pozza EA, Oride D (2003) Inoculação de Fusarium oxysporum f. sp. phaseoli em sementes de feijoeiro através de restrição hídrica. Ciência e Agrotecnologia 27:1023-1030.

Coutinho WM, Machado JC, Vieira MGGC, Guimarães RM, Ferreira DF (2001) Uso da restrição hídrica na inibição ou retardamento da germinação de sementes de arroz e feijão submetidas ao teste de sanidade em meio ágar-água. Revista Brasileira de Sementes 1:127-135.

Fancelli MI (1997) Doenças da cenoura. In: Kimati H, Amorim L, Bergamin Filho A, Camargo LEA, Resende JAM (Eds.) Manual de Fitopatologia. Vol 2. Doenças de plantas cultivadas. $3^{\text {a }}$ Ed. São Paulo SP. Ceres.

Farias CRJ, Del Ponte EM, Dal Magro T, Pierobom CR (2003) Inibição de germinação de sementes de trigo e milho em teste de sanidade em substrato de papel. Revista Brasileira Agrociência 9:141-144.

Ferreira DF (2000) Análises estatísticas por meio do SISVAR para Windows versão 4.0. Programa e Resumos da Reunião Anual da Região Brasileira da Sociedade Internacional de Biometria 45:235.

Halfed-Vieira BA, Lustosa DC (2000) Incidência de Alternaria dauci e A. radicina nas sementes de cenoura comercializadas na Zona da Mata em Minas Gerais. Fitopatologia Brasileira (Supl.) 25:460.

ISTA - International Rules for Seed Testing (2003) Annex to Chapter 7. Seed Health Testing Methods. Bassersdorf, Switzerland.

Limonard T (1968) Ecological aspects of seed health testing. Proceedings of International Seed Testing Association 33:343513.

Machado JC (1988) Patologia de Sementes: Fundamentos e Aplicações. Lavras. ESAL/FAEPE.

Machado JC, Oliveira JA, Vieira MGGC, Alves MC (2003) Controle da germinação de sementes de soja em teste de sanidade pelo uso da restrição hídrica. Revista Brasileira de Sementes 25:77-81.

Machado AQ, Machado JC, Vieira MGGC, Cassetari Neto D, Souza MV (2007) Potencial do uso da restrição hídrica em testes de sanidade de sementes de algodoeiro. Fitopatologia Brasileira 32:408-414. 
Magalhães FHL (2005) Restrição hídrica em patologia de sementes: novas aplicações. Tese de Doutorado. Universidade Federal de Lavras. Lavras MG.

Maguire JD (1962) Speed of germination-aid in selection and evaluation for seedling emergence and vigor. Crop Science 2:176-177.

McKinney HH (1923) Influence of soil temperature and moisture on infection of weat seedings by Helminthosporium sativum. Journal Agricultural Research 26:195-219.

Neergaard P (1979) Seed Pathology. $2^{\text {nd }}$. Ed. London. Macmillan Press.

Oliveira J A (1991) Efeito do tratamento fungicida em sementes e no controle de tombamento de plântulas de pepino (Cucumis sativus L.) e pimentão (Capsicum anum L.). Dissertação de Mestrado. Universidade Federal de Lavras. Lavras MG.
Pryor BM, Davis RM, Gilbertson RL (1997) Detection of soilborne A. radicina and its occurrence in California carrot fields. Plant Disease 82:891-895.

Soteros JJ (1979) Detection of Alternaria radicina and Alternaria dauci from imported carrot seeds in New Zealand. New Zealand Journal of Agricultural Research 22:185-190.

Souza RT, Forcelini CA, Reis EM, Calvete EO (2001) Freqüência de Alternaria dauci e Cercospora carotae como agentes da queima das folhas da cenoura em Passo Fundo, RS. Fitopatologia Brasileira 26:614-618.

Tylkowska K (1992) Carrot seed-borne disease caused by Alternaria species. In: Chelkowski J, Visconti A (Eds.) Alternaria: biology, Plant disease and metabolites. Amsterdam. Elsevier Science Publishers. pp. 429-457. 